Fecha de recepción: marzo 2017 Fecha de aceptación: octubre 2017 Versión final: marzo 2019

\section{Las performances musicales en las misiones jesuitas de guaraníes \\ Natalia Aguerre*}

\begin{abstract}
Resumen: Este artículo expondrá cómo la música, sonidos y canto/danzas fueron utilizados por los jesuitas en el proceso de intervención social de las comunidades guaraníes -del actual territorio argentino- durante la conquista española para la eliminación y resignificación de hábitos rituales guaraníes y la adaptación de conductas y actitudes, en clave cristiana.

Indagaremos en los primeros encuentros entre estos grupos para observar cómo los sacerdotes hicieron uso de la música con el propósito de provocar un tipo de sensibilización que les permitiera la reducción de los guaraníes. Observaremos cómo a partir de la constitución de las reducciones, los sonidos y canto/danzas guaraníes fueron re-significados y en qué medida los dramas estéticos musicales cristianos permitieron la creación de espacios de participación que llevaron a la internalización de nuevos comportamientos y sensibilidades. Para el análisis utilizaremos la categoría de performance como comunicación estratégica (Aguerre, 2015), entendiéndola como la escenificación pública de dramas estéticos dentro de un proceso de diseño sociocultural donde la sensibilización y participación actuaron como acciones estratégicas para la transformación social (Massoni y Pérez, 2009).
\end{abstract}

Palabras clave: música - performance - comunicación estratégica.

[Resúmenes en inglés y portugués en la página 74]

${ }^{(*)}$ Licenciada en Comunicación Social y Periodismo, Universidad Nacional de La Plata. Doctora en Comunicación, Universidad Nacional de La Plata. Profesora de grado y posgrado en la Facultad de Periodismo y Comunicación Social de la Universidad Nacional de La Plata; la Facultad de Diseño y Comunicación de la Universidad de Palermo y de posgrado en la Universidad de Quilmes. Integrante de equipos de investigación -UNLP, CLACSO-, que abordan temas sobre arte y política. Fundraiser y Gestora en Comunicación del Centro de Arte Experimental Vigo.

\title{
Introducción
}

Los vínculos de los jesuitas a los pueblos guaraníes estuvieron incentivados por las necesidades geopolíticas de la Corona española. Debido a que los portugueses, instalados 
en Brasil meridional, amenazaban expandirse hacia la colonia del Río de la Plata para así conquistar el Perú y el Alto Perú, la Corona española creó la provincia del Paraguay -1541- con sede en Asunción y dependencia en el Virreinato del Perú, con el objetivo de impedir y controlar el avance de la Corona portuguesa.

Los jesuitas fueron los encargados de reducir a las comunidades guaraníes, pero la intervención no solo implicó la concentración de estos grupos en las reducciones. Los sacerdotes debieron diseñar sus propósitos y acciones para dotar a esos espacios y a las funciones que en ellos se desarrollaban de un enlace simbólico, capaz de instituir una identidad cristiana marcada por saberes, valores, comportamientos, roles y jerarquías de poder mediante los que se organizaría la vida en el espacio misional.

En los primeros encuentros, el desconocimiento de las tribus por parte de los jesuitas hizo imposible establecer acciones programadas (Constituciones: art. 673). Sin embargo, en el marco de la misma acción y recurriendo a la persuasión pacífica (Acosta s. j., 1577: cap. VIII, par: 3), los sacerdotes pudieron lograr, paulatinamente, la reducción de los mismos. Dice el padre Ruiz de Montoya:

La entrada a sus tierras no era para pelear, pues no llevábamos armas, ni menos quitarles oro o plata, que no la tenían, sino a solo hacerlos hijos de Dios y enseñarles el buen modo de vivir; no se rindieron tan fácilmente, pero al fin se rindieron a las persuasiones (Ruiz de Montoya s. j., -1640- 1989, p. 112).

La persuasión representó una alternativa eficaz, en contraposición a la acción militar de los españoles, para la reducción de los guaraníes. Esta fue promovida mediante el uso de la cruz, las imágenes y la música como instrumentos de sensibilización y seducción. A medida que los sacerdotes lograban la aglomeración de los guaraníes en los nuevos espacios, los dramas estéticos europeos -imágenes, música- fueron utilizados como canales de sensibilización, transmisión del discurso cristiano y como medios de enseñanza; tal como lo establecía el Tercer Concilio limense -1582/1583-, el cual manifestaba: "Id a las iglesias por las mañanas, allí haced oración cada día, sin faltar ninguno y también a las tardes, tomando agua bendita y besando la cruz y mirando las imágenes" (Tercer catecismo y exposición de la doctrina cristiana por sermones 1585: sermón XXVIII). Pero además de haber servido para exhibir y enseñar los símbolos cristianos, las manifestaciones estéticas fueron un medio para la adaptación y eliminación de determinados aspectos culturales de los guaraníes, como también un canal para reintegrar a la mayor cantidad de indígenas a la nueva configuración social.

Debido a ello, los sacerdotes diseñaron una política sociocultural a partir de la cual establecieron los talleres de artes y oficios, en los que pudieron crear espacios de participación activa de los guaraníes (Massoni y Pérez, 2009), a partir de las distintas prácticas de producción de los dramas estéticos. De esta manera, los jesuitas buscaban la "producción de un habitus" (Bourdieu, 2007, p. 86), conformado por estas rutinas de trabajo y la asistencia diaria a los ritos cristianos. Junto con ello, las actividades en estos talleres les permitieron a los curas imponer nuevos roles y jerarquías de poder para ejercer el control de policía (Foucault, 2011) y fortalecer sus vinculaciones con este sector social. 
Por lo expuesto, consideramos a los dramas estéticos en tanto performance como comunicación estratégica (Aguerre, 2015), ya que estas expresiones con características de entretenimiento se articularon con el drama social -prácticas rituales que fueron adaptadas, eliminadas o transformadas producto del encuentro entre ambas culturas- para promover mediante escenificaciones públicas una eficacia política; a partir de un diseño estratégico que comprendía acciones de sensibilización y participación para la reintegración de la comunidad guaraní en los espacios de reducción (Turner, 1987, 1988; Schechner, 2000, 2007). A través del uso del drama estético como aspecto constitutivo de la performance, los jesuitas apelaron a la sensibilización -considerada como un elemento de importancia para la Orden ignaciana ${ }^{1}$ - y la participación para crear trabajos comunitarios; roles; jerarquía de poder; producir emociones y motivar la apropiación de los valores cristianos y la identificación con ellos.

\section{Sonidos, música y canto/danza}

En los primeros encuentros, los sonidos y música actuaron como instrumentos de sensibilización y atracción de los guaraníes.

Los jesuitas, navegando por los ríos, echaron de ver que cuando para explayarse santamente cantaban cánticos espirituales acudían a oírlos tropas de indios y parecían tener en ello gusto especial. Aprovechándose de él para explicarles lo que cantaban; y como si tal melodía hubiera cambiado sus corazones, haciéndoles susceptibles de los afectos que les quería inspirar, no tenían dificultad en persuadirles a que los siguiesen, los hallaban dóciles y poco a poco hacían entrar en sus ánimos los grandes sentimientos de la religión. (Charlevoi II, 1912, p. 60, en Chamorro, 2004, p. 252)

Como lo señala el padre Cardiel, "cuando los primeros misioneros vieron que estos indios eran tan sensibles, pusieron especial cuidado en la música para atraerlos a Dios" (Cardiel s. j., -1747/1770-, 1994, p. 102). Esta predisposición de los guaraníes hacia los sonidos y la música estaba marcada por sus prácticas rituales en los cantos/danza. Estos eran el momento y lugar donde se estructuraban las funciones de los karai/chamanes, "donde los hombres se dicen y se vuelven dioses, donde se cantan las palabras inspiradas" (Meliá s. j., 1997, p. 128). La danza ritual y los cantos fueron la forma en que los guaraníes expresaban su religiosidad, pero también la manera en que las rebeliones indígenas afirmaban su identidad frente a las otras tribus (Chamorro, 2004).

Los guaraníes conformaban una sociedad de guerreros producto de un estado conflictivo entre grupos que se disputaban -en algunos casos- el mantenimiento de la legitimidad de los líderes y, en otros, el requerimiento de amplios territorios para la agricultura de siembra ${ }^{2}$. A través de la danza, el canto y el ñe 'e ayvu -traducido como palabra que denota voz, habla, lenguaje, idioma, alma, nombre, vida, personalidad, origen (Ruiz de Montoya s. j., 1640)-, los karai/chamanes podían manifestar sus mitos, realizar los rituales de nombramientos, conectarse con sus antepasados y manifestar -ante las tribus enemigas- su 
identidad de origen. "Muchos se ennoblecen con la elocuencia en el hablar, tanto estiman su lengua y con razón porque es digna de alabanza y de celebrarse entre los de fama con ella agregan gente y vasallos". (Ruiz de Montoya s. j., -1640- 1989, p. 149)

Tal como lo expresaba el padre Ruiz de Montoya en sus registros, las palabras cantadas eran de gran importancia en la comunidad guaraní, a tal punto que éstas actuaron como manifestaciones de resistencia por parte de sus líderes frente a los jesuitas como nos hace saber el padre Lozano en una de sus vínculos y contactos en una comunidad:

Oberá se tomó su tiempo en el camino hacia el Paraná, goza de placeres torpes. Mantuvo una multitud de concubinas con las que se ocupó en los bailes abominables y compuso canciones para su propia alabanza, y él persuadió a todos los demás de que si así desean permanecer en su favor, entonces deberían hacer lo mismo día y la noche. Ellos le obedecieron con prontitud, ya que la licencia para hacer el vicio es la más poderosa ayuda para reunir la obediencia entre los bárbaros. Todo el tiempo que no se dirigían a infestar Asunción pasaron a cantar alabanzas a su adorado Oberá, ensalzando su poder y majestad, y otros atributos que se atribuía en su orgullo diabólico. El peligro en la provincia creció por momentos debido a la comitiva y la potencia de Oberá, atrayendo indios de partes distantes a adorar esta fabulosa deidad. (Lozano s. j., 1874, pp. 21, 24)

Los jesuitas consideraban que debían eliminar a los karai/chamanes no sólo por ser los líderes religiosos sino porque mediante las palabras cantadas, éstos convocaban a sus tribus para impedir la transmisión de las nuevas ideas cristianas.

Cubierto con una capa de plumas que suenan las castañuelas hechas de cráneos de cabra y saltando como locos, él demandó que él era el verdadero señor de la muerte, de las mujeres y de los granos; que todo estaba sujeto a su voluntad, que con su aliento podría aniquilar el mundo y volver a crearlo, que él era un dios en tres personas, que a través de su ritual que había dado el ser a su esclavo. (cit. de Chicago-Córdoba, 1993, en Wilde, 2007, p. 51)

Según los sacerdotes, los karai/chamanes también ponían en riesgo la estabilidad de la vida en la misión. Como plantea el antropólogo Haubert (1991) en los ritos religiosos y guerreros, los karai/chamanes se apoderaban del cuerpo de uno de sus adversarios para comérselo como símbolo de dominación y legitimación de sus líderes.

La antropofagia no se trata sólo de saciar el hambre. El rito exige la reparación, el rapto de energía vital en el grupo victorioso a los que matan a un enemigo o le hacen prisionero, el que ejecuta al guerrero cautivo, los que comen de su carne o simplemente lo tocan, aunque sea con un palo. Los niños que abren el cráneo con pequeñas hachas de cobre y empapan sus manos en sangre, todos se engrandecen, adquieren fuerza y cambian el nombre. La antropofagia y la guerra tienen en si una función social esencial. (cit. de Haubert, 1991, p. 28, en Herraiz, 2006, p. 4) 
Así lo relata Ruiz de Montoya s. j., al pretender ingresar a la provincia de Tayaobá.

Dieron muestras de recibirme bien, pero fingidas, porque dado aviso de mi llegada, toda aquella noche fue desgalgando gente de aquellas sierras con ánimo de comerme y a los que iban en mi compañía. (...) El que más ardía en furor y deseos de comerme era un mago llamado Guirabera, el cual se hizo llamar Dios y con sus mentiras se había apoderado de esa gente. (Ruiz de Montoya s. j., $-1640-1989$, p. 123)

En lo que fuera la reducción de Loreto, también manifiesta que:

Salimos el P. José y yo por aquellos ríos a convidar a los indios a que se redujesen en poblaciones grandes, en puestos que ya se le habían señalado. Llegamos a un pueblo cuyo gobernador era un cacique, gran mago y hechicero y familiar amigo del demonio, llamado Taubici, que quiere decir, diablos en hilera o hilera de diablos. Era muy cruel y con cualquier achaque hacía matar indios a su antojo, y así era respetado y servido a pensamiento. (Ruiz de Montoya s. j., $-1640-1989$, p. 73 )

No sólo se pretendía erradicar la figura de los karai/chamanes sino que, además, tenían que re-significar los sonidos y las palabras cantadas, a partir de las cuales se constituía la identidad guaraní. A través de la observación y registro (Carballeda, 2008) de las prácticas guaraníes, Ruiz de Montoya s. j. describe cómo los "alaridos" eran utilizados frente a la muerte de un integrante de la comunidad guaraní.

Reciben a los huéspedes o a los que vienen de viaje con un formado llanto de voces. (...) Salen luego las dos mujeres y rodeando al huésped, sin haberse hablado palabra, levantan ellas un formal alarido. (...) Los varones cubren el rostro con las manos mostrando tristeza y llorando juntamente. Cuanto más importante es la persona, mayores son los alaridos que semejan que alguien muy querido de la comunidad ha muerto. (Ruiz de Montoya s. j., -1640- 1989, pp. 31, 32)

Los jesuitas captaron estos sonidos como signos de comunicación para re-significarlos en términos cristianos y para usarlos en determinados ritos religiosos. Un ejemplo de ello, lo presenta el padre Escadón cuando describe un funeral cristiano.

En el momento del entierro los monaguillos van por el difunto con el Padre, vestido con una capa de lluvia negra, y los músicos y, a partir de ahí, el cortejo fúnebre se ordena a la iglesia, en la que el elogio se canta, etc (...). Mientras que el cuerpo es puesto en el sepulcro, los gritos de la madre, esposa o parientes comienzan con un tipo de canto lúgubre que es tan disonante que es imposible de explicar. Esta canción o gemido, en su guahú lengua o lamentación, es cantado por las mujeres. En ella cantan, lloran o hablan sobre el fallecido diciendo 
no solo lo que era, pero lo que se esperaba que hubiera sido si no hubiera muerto. (Escadón s. j., -1769-, en Furlong s. j., 1965, p. 78)

A los sonidos guaraníes re-significados se les sumaron los impuestos por la religión cristiana. Los jesuitas recurrieron a la estimulación sensitiva, a través de las campanas y los tambores, para marcar el orden temporal en las rutinas diarias.

El sonido de las campanas y los tambores -los que se utilizaban para guiar a las poblaciones a través de diversas actividades y rituales diarios- hacía que los guaraníes supieran cuándo eran convocados para la misa, el trabajo, la comida, la confesión, la oración. (Singer, 2009, p. 47)

El padre Ruiz de Montoya refiere a cómo organizaban al pueblo para que asistiesen a la misa en los primeros tiempos de las reducciones: "padecíamos en una reducción un gran trabajo, que estando toda la semana hirviendo el pueblo de gente, solos los domingos cuando a voz de muchas campanas queríamos juntar el pueblo al sermón y Misa" (Ruiz de Montoya s. j., -1640-1989, p. 131). Mientras que el padre Cardiel nos ofrece información sobre esta disposición temporal hacia mediados del S. XVIII. (Ver Figuras 1 y 2)

A las 4 y media de la mañana se toca la campana de la torre a las Avemarías: a las 4 y media a oración mental. A las cinco y cuarto abre la puerta el portero para que entren los sacristanes y cocinero. A las 5 y media, a salir de oración con la campana chica de los padres, y con la de la torre a misa. (...) A las diez y cuarto a examen: después de comer, quiete o conversación, en que también se toca a salir. Siesta hasta las dos. A las dos se toca la campana grande. (...) A las cinco a rezar los muchachos y pregúntales la Doctrina un Padre: acabada ésta, toca la campana grande al rosario. (...) A las siete en verano y a las 8 en invierno se toca la campana para cenar. (Cardiel s. j., -1747/1770- 1994, p. 95)

"A la intuición meteorológica se contrapone, por lo tanto, el intervalo regular de la campanada litúrgica, cuyo orden es el principal gobierno de la Iglesia" (Valenzuela Márquez, 2001, p. 364). Como ya manifestamos, el sonido de las campanas convocaba a los guaraníes a las prácticas rituales y a las laborales pero, también, las mismas eran concebidas como expresión del poder de Dios.

Estaba yo por este tiempo en Loreto cubriendo un campanario, en que tenía una buena campana que su Majestad nos había dado; turbose un pensamiento de que un indio de los que trabajaban se hacía caer del campanario y morir sin confesión y quebrar la campana, me acogí al Santísimo Sacramento (que ya lo había colocado) y suplíquele que si algo de aquello había de suceder se refundiese todo en la campana, porque sentiría mucho ver un indio muerto sin confesión: esto fue sábado en la tarde; tocose varias veces la campana aquel día, y a la noche al Ave María y después a las ánimas; el día siguiente al primer toque que se dio con ellas sentimos quebrada: me consoló mucho su pérdida 


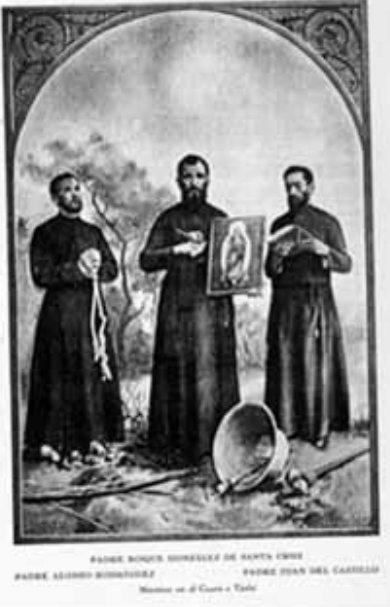

Figura 1.

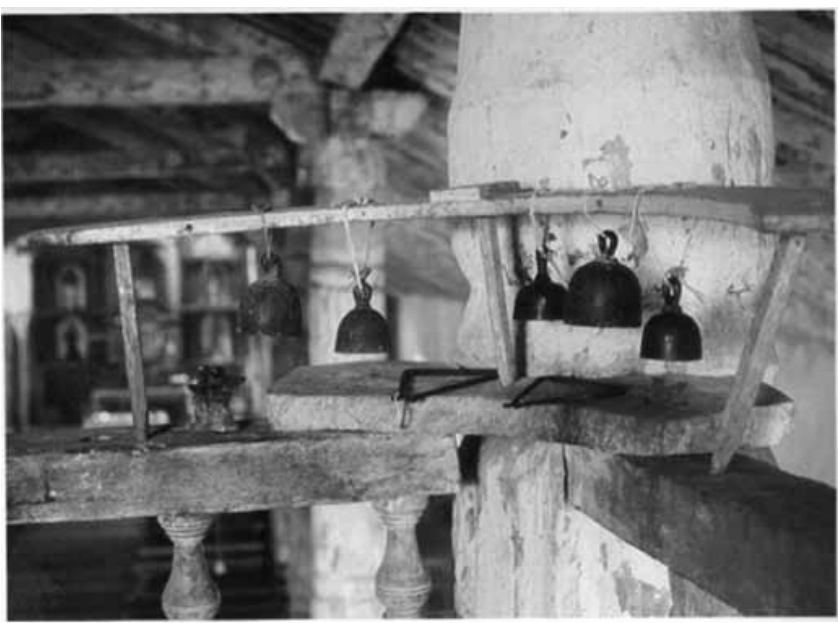

Figura 2.

Figura 1. Blanco, J. M (1929): “Jesuitas mártires del Caaró: Roque González de Santa Cruz, Alonso Rodríguez y Juan del Castillo". Ed. Amorrartu. Figura 2. Las pequeñas campanas de la aldea de Santa Ana, en la región de Chiquitos, Bolivia. Foto de: Szarán, Luis y Ruiz Nestosa, Jesús (1999): "Música en las reducciones jesuíticas de América del Sur". Asunción. Colección de Instrumentos de Chiquitos, Bolivia. Fundación Paracuaria, Missionsprojur S.J. Nürnberg, Centro de Estudios Paraguayos “Antonio Guasch".

por la ganancia del indio. Apenas habían pasado tres horas cuando el P. José me escribió de San Ignacio (que estaba tres leguas de Loreto) preguntándome si era verdad que estaba quebrada la campana, porque en amaneciendo se había aparecido el demonio a algunos indios, y les había dicho: Mirad mi poder, yo vengo ahora de quebrar la campana de Loreto. (Ruiz de Montoya s. j., -1640 1989, pp. 100, 101)

Este relato revela la importancia que se le otorgaba a este instrumento. Ruiz de Montoya s. j. "suplica" al Santísimo que quiebre la campana antes de que un guaraní pierda la vida. Para el padre, ella representaba un medio de manifestación de Dios -aunque creyeron que fue el "demonio", el que tuvo el poder de quebrarla-. Esto demuestra que la campana era un elemento usado como intermediario ante la divinidad; su sonido portaba una carga sagrada que marcaba el pulso vital del tiempo en el espacio misional recordando la presencia divina. 
La Iglesia confirmaba, de esta forma, un rol globalizador que apuntaba al control del universo mental de la comunidad en todos sus intersticios sensibles. Al lado de la palabra persuasiva, de la imagen y del ritual emotivo, el lenguaje de sus campanas sobrevolaba de día y de noche, recordando la omnipresencia de las fuerzas divinas y de sus interlocutores institucionales. (Valenzuela Márquez, 2001, p. 365)

El relato también nos muestra la circulación de información entre los sacerdotes en el espacio jesuítico-guaraní. Junto a las cartas Annuas -que los curas provinciales debían mandar al Prepósito General; es decir al Padre General de la Compañía en Roma-, también se producía correspondencia entre quienes estaban al frente de cada reducción para que éstas "ayuden a unir a los repartidos con su cabeza y entre sî" (Constituciones: art. 673).

Las cartas entre los sacerdotes del espacio jesuítico-guaraní, como las Annuas, refieren a situaciones en las que "la emisión del enunciado implica la realización de la acción" (Austin, 1955, p. 8). En estos textos performativos (Austin, 1955, p. 9) no se encuentra tan sólo la descripción de un hecho particular sino que se realiza la acción de tener que escribir un relato moralizante. Así lo expresa Ruiz de Montoya s. j., en relación al demonio: "mirad mi poder, yo vengo ahora de quebrar la campana de Loreto" (Ruiz de Montoya s. j., -16401989, p. 101).

Estos relatos entre los padres del espacio jesuítico-guaraní son destacables, en la medida que -y en función de ellas- éstos pudieron hacer "que todo funcione, por órdenes repetidas de los generales (...) y la continua práctica de avisos entre poblaciones" (Cardiel s. j., -1747/1770-1994, p. 88). De esta manera, podemos inferir que los jesuitas apelaron a estrategias comunes para la organización sociocultural de la vida en la misión, como lo demuestra el padre Cardiel en la cita siguiente, en relación a las prácticas musicales.

Todas las reducciones tienen 30 o 40 músicos. A los indios se les enseña desde la infancia y gracias a la perseverancia y la seriedad de la enseñanza, se convierten en músicos o cantantes calificados. He pasado por Europa y en pocas catedrales he escuchado una música mejor que éstos. (Cardiel s. j., -1747/17701994, p. 102)

La práctica musical -ejecución de instrumentos y cantos- y producción de objetos -en los talleres y escuelas de música-, también se constituía como momentos y espacios de control (Foucault 2011) mediante la vigilancia en los trabajos, la disciplina en la labor y el aprendizaje de los cantos como de los instrumentos.

Las performances musicales requerían de una participación activa -trabajo, educación musical $^{3}$ - y una contemplativa en los momentos de exhibición. Estas se realizaban en escenarios públicos - plazas y calles-, en función de las celebraciones religiosas o civiles, y en las iglesias en ocasión de las misas. "La música de todos los días en la iglesia que duraba mientras duraban las misas, es decir casi toda la mañana, repartida en dos coros uno frente al otro de modo que cesando uno recomenzaba el otro a su turno" (Strabel s. j. -1705-, en Furlong s. j., 1962, p. 491). 
Los jesuitas conformaron coros y orquestas e introdujeron instrumentos europeos -que fueron reproducidos por los guaraníes- para la representación de los dramas estéticos musicales impuestos por la Contrarreforma: himnos, villancicos, letanías, etc. Por los inventarios realizados durante el proceso de expulsión de los jesuitas, podemos conocer una notable cantidad de objetos musicales diferentes que fueron elaborados durante el período de convivencia (Furlong s. j., 1962, pp. 675, 690). También sabemos -por el relato de los padres-, que en la reducción de Yapeyú se estableció la escuela de música para los guaraníes. Dice el padre Furlong:

Yapeyú no solo llegó a ser un gran emporio musical, por la escuela musical que allí se fundó y a la que acudían hasta de las ciudades españolas, sino también por haber llegado a ser el gran taller de toda clase de instrumentos musicales, órganos, arpas, violines, trompas, cornetas, chirimías, y toda clase de instrumentos musicales que eran allí fabricados con singular destreza y exportados a las reducciones de indígenas y a las ciudades españolas. (Furlong s. j., 1962, p. 487)

Junto a la enseñanza de la música, los guaraníes también aprendieron las danzas europeas.

Por medio de maestros seglares se introdujo esta enseñanza en los indios y estos aprendieron tan bien, que ya sirven de maestros unos a otros. Y así en cada pueblo formase cuatro cuadrillas de a ocho danzantes que de ordinario son los mismos que aprenden la música. (Insignes misioneros de la Compañía de Jesús en la provincia del Paraguay. Pamplona 1687, p. 23, en Furlong s. j., 1962, p. 489).

A diferencia de la música -que era ejecutada todos los días-, las danzas sólo se realizaban los domingos y en las festividades o procesiones religiosas y civiles.

No menos atraen las danzas de los niños a los grandes a la iglesia, teniendo por suma dicha de sus hijos el verlos galancitos danzar en las festividades y procesiones con raro primar. Porque un niño de ocho años hará 50 mudanzas sin perder el compás de la vigüela o harpa, con tanto aire como el español más ligero. (Jarque s. j., -1662-, en Furlong s. j., 1962, p. 489)

Con esta descripción notamos que la performance responde a un drama español -reglas de composición- que, en función de una puesta en escena, fue exhibido en el espacio de la iglesia donde los niños ejecutaron "50 mudanzas sin perder el compás de la vigüela o harpa"; es decir, teniendo una disciplina en la destreza de la danza y, por ende, en el dominio del cuerpo que a su vez representaba el concepto de persona cristiana. "Las reglas y normas de comportamiento religioso son prácticas de control del cuerpo y, en este sentido y dentro del horizonte americano colonial, funcionaron como mecanismos de interiorización de los fundamentos filosóficos, morales y éticos”. (Araya Espinosa, 2006, p. 349) 
Pero además de interiorizar a la persona cristiana, el cuerpo debía representar el ideal civil español.

Salen en una danza doce danzantes chicos y grandes, todos con instrumentos musicales, danzando y tocando a un tiempo, sin que los músicos les hagan el son. Los dos primeros con violines y vestidos de españoles mientras los segundos con pequeñas arpas amarradas con cintas a la cintura. (Cardiel s. j. -1770-, en Furlong s. j., 1962, p. 489)

En este sentido, la performance operó desde el drama estético hacia el drama social, en tanto que su exhibición no representaba "simplemente un hacer sino un mostrar que se hace" (Schechner, 2000, p. 21). A partir de la elección de los danzantes y de la enseñanza y repetición de las figuras de baile -ensayo-, los jesuitas transformaron las conductas y los modos de actuación -restauración de la conducta (Schechner, 2000, p. 109)-. Así, los danzantes/actores comunicaban a los miembros de la comunidad/espectadores bajo qué formas debían actuar en sus vidas cotidianas y qué valores debían adoptar, en virtud de los personajes que en ellas se representaban. El padre Matías Strabel nos brinda otro ejemplo:

Ellos mismos tocaban y bailaban al mismo tiempo, pero con tal rigor en la cadencia y con tal orden y control en las figuras, que se ganaban el aplauso y la aprobación de todos. Lo mismo era con todas las otras danzas, en las cuales lo más admirable, a mi parecer, era aquella exactitud del tiempo y del orden, si errar un ápice por más largos que fuesen y aunque los bailasen, a veces, 16 o 24 veces. (Strabel s. j., -1705-, en Furlong s. j., 1962, p. 491)

En esta performance se puede observar la eficacia de la conducta restaurada (Schechner, 2000), realizada a través de la repetición/ensayo del drama: "con tal orden y control de las figuras que se ganaban el aplauso y la aprobación de todos". Igualmente, estas exhibiciones no dejaban de ser una dispersión: "todas estas cosas sirven para honesto entretenimiento en sus pueblos para que por los ojos y con decente deleite del alma y cuerpo les entre las cosas de Dios" (Cardiel s. j., -1770-, en Hernández s. j., 1913, p. 534). Un entretenimiento que provocaba sensibilización y la propensión a pautas morales, a partir de los temas danzados.

Hay también variedad de danzas de ángeles y de ángeles y diablos con el traje correspondiente, peleando unos con otros; y otras en que trayendo cada uno tableta en la mano pintada y poniéndola cada uno sobre una mesa, una sobre otra, tras cada mudanza representan al fin una perfecta imagen de la Virgen María, de San Ignacio o de otros. (Cardiel s. j., -1770-, en Hernández s. j., 1913, p. 535)

Apelando al estímulo sensorial -danza, imágenes- la estructura dramática de esta performance incorporó el conflicto entre los ángeles y el diablo para transmitir los conceptos de bien y mal cristiano, y reafirmar un modelo identitario de conducta que se consolidaba y se distinguía de otro. 
A diferencia de las performances de la imaginería (Aguerre, 2015), la representación de la música y la danza no presentaba roles jerarquizados de poder. "Las producciones sonoras eran concebidas de formas abiertas, flexibles y plurales" (Wilde, 2007, p. 1). Por ello, a partir de la sensibilización -provocada por los sonidos y la música- y la participación trabajo, ensayos, puestas en escena/público- como estrategias de comunicación (Massoni y Pérez, 2009) de la performance, se orientó a la acción de re-significación y apropiación de un tipo identitario de conducta y alteridades.

Ante lo expuesto, podemos afirmar que los cantos/danzas guaraníes fueron transformados de hábitos rituales a prácticas singulares que, si bien se desarrollaban en los nuevos ritos cristianos, permitieron la integración de los guaraníes a las rutinas diarias mediante la conformación de escuelas, grupos instrumentales, corales y de bailes. De este modo, la música y los bailes posibilitaron la creación de espacios para la producción, aprendizaje y ensayos, y la participación de los guaraníes que, enmarcados en una misma actividad, permitían generar la sensación de pertenencia y permanencia hacia ese colectivo.

La eficacia de estas performances musicales puede evidenciarse por los relatos realizados luego de la expulsión de los jesuitas, en los cuales se manifiesta que la música siguió siendo ejecutada por los descendientes de los guaraníes. Por el obispo diocesano Monseñor Sebastian Díaz Larangiera, sabemos que en el pueblo de San Luis -hacia 1864- los guaraníes continuaron celebrando la Semana Santa entonando -en su lengua- algunos cantos. Sorprendido al ver que sus descendientes de aquellos indios civilizados por los jesuitas desterrados hacía una centuria, conservaban las mismas tradiciones musicales enseñadas por sus maestros y así todo el canto de la Semana Santa era en guaraní, Hemeterio Velloso da Silveira, que los oyó cantar, tomó nota de esos cantos.

\begin{tabular}{|l|l|}
\hline Cristo Señor Nuestro & Cristo Nhandejara, comi borara acuerá y \\
Líbranos Señor & quatia picera \\
De nuestro pecado & Nhamdemoñaangara \\
Perdónanos, Cristo Señor Nuestro (bis) & Ah! Cristo nhandejara (bis) \\
Por las antorchas con que te buscaron & Conde quarepotyyocua acuerá \\
Los crueles judíos & Nhamdemoñaangara yocuá pirera \\
Por nuestros pecados & Ah Cristo nhandejara \\
Perdónanos, Cristo Nuestro Señor & Conde, tatahende, heca heca acuerá \\
Por la espada & Nhamdemoñaangara heca heca pierá \\
Con la cual, San Pedro & Ah! Cristo, nhandejara". \\
Pretendió defenderte & \\
De los crueles judíos & \\
Perdónanos, Cristo Nuestros Señor. & \\
\hline
\end{tabular}

(Velloso da Silveira 1864, en Furlong s. j., 1962:. 489). 


\section{Conclusión}

La intervención social jesuítica delineó un diseño estratégico en su labor evangelizadora produciendo el conocimiento de los elementos socioculturales de los pueblos guaraníes a intervenir. Esto les facilitó a los sacerdotes la elección de acciones para viabilizar el diálogo y las relaciones entre los actores comprometidos (Acosta s. j., 1577; Carballeda, 2008), en virtud de la transformación de determinados principios sistémicos de la comunidad -nociones de identidad, alteridad, roles y jerarquías de poder-, los cuales colaboraron en el establecimiento y sostenibilidad del orden sociopolítico impuesto.

Por lo expuesto, consideramos que las performances musicales fueron utilizadas como un instrumento de diseño comunicacional estratégico para lograr la interacción entre los actores comprometidos como también para bridar forma al proceso social de intervención. Es así que a partir de la información obtenida de la comunidad guaraní y de las puestas en escena rituales, los jesuitas pudieron transmitir y marcar los nuevos modos de vinculación con el cuerpo, con el trabajo, con la noción de alteridad, con las ideas y creencias mitológicas y con los estatutos y roles de poder mediante las estrategias de sensibilización y participación comunitaria.

Debido a ello, es que entendemos a la performance como un instrumento de diseño político y práctica comunicativa donde los sentidos y significaciones de cada cultura interactúan, pero también manifiestan sus luchas simbólicas -materializadas en la tensión sujeto cristiano/ser guaraní-, generando cambios sistémicos y proactivos en la dinámica sociocultural de los grupos comprometidos en este proceso de intervención social.

\section{Notas}

1. Ver 1ra. anotación de los Ejercicios Espirituales. Versión digital, en: www.ejercicioses pirituales.com

2. La rotación de los cultivos imponía una forma de ocupar el espacio que permitía mantener el equilibro entre la población y los recursos. "La tierra origina ciclos que no son solo económicos sino socio-políticos y religiosos" (Chamorro, 2004, p. 65). Es probable que esa consciencia de la dependencia de la tierra esté en la base de las celebraciones del maíz nuevo, de los frutos maduros y de la revelación del nombre (Clastres, 2007).

3. Uno de los primeros maestros de música que llegó al espacio jesuítico-guaraní fue el padre Juan Vaisseau (1583-1623), natural de Bélgica donde había trabajado como músico profesional. Arribó a Paraguay en 1617, dejando el cargo de músico oficial de la corte de Carlos V. Junto con él, Luis Berger (1589) -que no era sólo un músico, sino también pintor y maestro de baile- y el padre Antonio Sepp (1691) se dedicaron a la enseñanza musical.

\section{Referencias Bibliográficas}

Acosta, J. de s. j. (1577). De Procuranda Inorum Salute. Recuperado de: www.cervantesvirtual. com/predicacion-del-evangelio indias. 
Araya Espinoza, A. (2006). El castigo físico. El cuerpo como representación de la persona, un capítulo en la historia de la occidentalización de América S. XVII-S. XVIII. Santiago de Chile, Chile. Revista de Historia Vol 2. (No 39), pp. 20, 25 Instituto de Historia Pontificia. Universidad Católica de Chile.

Austin, J. (1955). Cómo hacer cosas con palabras. Barcelona: Paidos Ibérica.

Blanco, J. M. (1929). Historia documentada de la vida y gloriosa muerte de los padres Roque González de Santa Cruz, Alonso Domínguez y Juan del Castillo. Buenos Aires, Argentina: Ed. Amorrortu.

Carballeda, A. (2008). Los cuerpos fragmentados. Buenos Aires, Argentina: Ed. Paidós.

Chamorro, G. (2004). Teología guaraní. Recuperado de: www.books.google.com

El Concilio de Trento. Recuperado de: www.books.google.com

Constituciones De La Compañía De Jesús. Recuperado de: www.bib.cervantesvirtual.com

Furlong, G. s. j. (1962). Misiones y pueblos guaranies. Buenos Aires, Argentina: Ed. Biblioteca del Colegio El Salvador.

Massoni, S. y Perez, R. (2009). Hacia una teoría general de la estrategia. Buenos Aires, Argentina: Ed. Ariel Comunicación.

Herraiz Labrador, C. (2006). Las reducciones del Paraguay. Madrid, España. Recuperado de: www.dialnetunrioja.es

Lozano, P. s. j. (1874). Historia de la Conquista del Paraguay, Río de la Plata y Tucumán. Recuperado de: www.eBooks and Texts. American Libraries/archive.org

Ruiz De Montoya, A. s. j. (-1560/1570-1991). "Silex del Divino amor". Lima, Perú: Ed. Pontificia de la Universidad Católica.

Ruiz De Montoya, A. s. j. (-1640- 1989). "La Conquista espiritual del Paraguay”. Rosario, Santa Fe: Ed. Equipo Difusor de Estudios de Historia Iberoamericana.

Schechner, R. (2007). "Performance theory". New York, USA: Ed. Routledge.

Sebastian, S. (1985). “Contrarreforma y barroco”. Buenos Aires, Argentina: Ed. Alianza Forma.

Sepp, A. s. j. (-1691/1733-1971). "Relación de viaje a las misiones jesuíticas”. Buenos Aires, Argentina: Ed. Eudeba.

Sepp, A. s. j. (-1709-1973). “Continuación de las labores apostólicas”. Buenos Aires, Argentina: Ed. Eudeba.

Turner, V. (1987). From ritual to theatre. New York, USA: Ed. Performing Arts Journal Press.

Turner, V. (1988). The Anthropology of Performance. New York, USA: Ed. The Performance Arts Journal Press.

Wilde, G. (2007). Music and polities. Toward and political anthropology of mision sound: Paraguay in the 17th and 18th centurias. Recuperado de: www.music.ucs.lo.edu

Wilde, G. (2009 -a-). Religión y poder en las misiones de guaranies. Buenos Aires, Argentina: Ed. Paradigma Indicial.

Wilde, G. (2009 -b-). Imágenes, sonidos y memoria. Hacia una antropología del arte misional. in Histoire de l'art et anthropologie, Paris, coédition INHA / musée du quai Branly ( Les actes »), 2009, [En ligne], mis en ligne le 28 juillet 2009, Consulté le 31 août 2017. URL : http://actesbranly.revues.org/316. 


\begin{abstract}
This article will attempt to explain how music, sounds and singing/dancing used by the jesuits along the process of social intervention of argentinian guarani communities during the Spanish Conquest in order to remove and re-significate guarani rituals habits and adapt them to christian mood. We will investigate the first encounters between the two groups to observe how those priests used music as a means to prompt guarani sensitiveness which would allow the jesuits reduce the guarani. We shall then observe how, after the constitution of these reductions guarani, sounds and singing/dancing were resignificated ant them, to what extent these christian aesthetic musical drama allowed the jesuits the creation of actions where the guarani could internalize new behavious, habits and sensibilities. For the analysis we shall use the category of performance as a strategic communication (Aguerre, 2015) defined as the public scenification of aesthetic drama within a process of cultural and social design where sensitiveness and participation were strategic actions for social transformation (Massoni y Pérez, 2009).
\end{abstract}

Key words: music - performance - strategic communication.

Resumo: Este artigo irá expor como música, sons e canto / dança foram usados pelos jesuítas no processo de envolvimento social das comunidades Guarani-da actual território argentino durante a conquista espanhola para a remoção e re-significação de rituais e hábitos Guarani adaptação de comportamentos e atitudes, em um cristão. Vamos investigar nas primeiras reuniões entre esses grupos para ver como os sacerdotes tomaram a música com o objetivo de provocar uma espécie de consciência de que lhes permitiria reduzir o Guarani. Observe como a partir da constituição das reduções, sons e cantando / dançando Guarani foram e-significados re até que ponto dramas estéticas musicais cristãos permitiu a criação de oportunidades de participação que levou à internalização de novos comportamentos e sensibilidades. Para a análise vai usar a categoria de desempenho como comunicação estratégica (Aguerre, 2015), entendido como a encenação pública de dramas estéticos dentro de um processo de reintegração social (Turner, 1987), onde a consciência ea participação agiu como ações estratégicas para a transformação social (Massoni y Perez, 2009).

Palavras chave: música - performance - comunicação estratégica. 